\title{
LA HABANA Y SU REGIÓN: UN PROYECTO DE ORGANIZACIÓN ESPACIAL DE LA PLANTACIÓN ESCLAVISTA
}

\author{
POR \\ CARLOS VENEGAS FORNIAS \\ Centro de Conservación y Restauración de Monumentos, \\ La Habana
}

La ciudad y su región experimentaron entre 1790 y 1810 un crecimiento acelerado de la producción azucarera basada en la plantación esclavista. Esto implicaba planear la acción sobre un territorio más amplio, desde diferentes ángulos como el poblamiento, la mano de obra, las fuentes de energía, la comunicación y el transporte, la urbanización y otros aspectos que por vez primera eran tratados bajo la óptica de un programa general, con criterios inspirados en el espiritu reformista de la ilustración.

El artículo realiza una sintesis de las iniciativas, de sus protagonistas $y$ aportes con la intención de evaluar la trascendencia de este momento de despegue intelectual en la organización urbana de la ciudad y su región.

Durante los veinte años que transcurrieron entre 1790 y 1810, la ciudad de La Habana y su región experimentaron una transformación profunda causada por el crecimiento de las plantaciones esclavistas. Desde entonces quedaron planteados

SigLAS UTILIZADAS

ANC: Archivo Nacional de Cuba, La Habana.

CM: Colección de Manuscritos de la Biblioteca Nacional «José Martí», La Habana. 
algunos de los temas esenciales para el desarrollo del país, vigentes hasta la ruptura producida entre 1868 y 1886, con la primera guerra de independencia y la abolición de la esclavitud (1).

La transformación obedeció a los intereses de los propietarios criollos, dueños de la tierra y de riquezas acumuladas gracias a la función de puerto-escala y plaza-fuerte que había desempeñado la ciudad por dos siglos dentro del sistema de monopolio. Estos sellaron un compromiso tácito con la monarquía española sobre un objetivo común: la necesidad de liberar el comercio e impulsar los cultivos. Mientras en otras colonias americanas se gestaban las contradicciones que conducirían a las guerras de independencia, los hacendados cubanos se inclinaron hacia las reformas, en plena coincidencia con las tendencias reformistas e ilustradas de la metrópoli, logrando concesiones como la libertad de la trata y del comercio con extranjeros neutrales, y concentraron sus esfuerzos en convertir su región en la sustituta de la devastada colonia francesa de Haití, en cuanto a producción de azúcar y café.

Para lograr este propósito la ciudad contaba con un grupo de hombres, nacidos y educados en ella, capaz de encauzar un amplio repertorio de asuntos relacionados con la colonización rural, las comunicaciones, la seguridad o defensa, el desarrollo de la industria, las fuentes de energía, el orden urbano, la educación y otros, que exigían conocimientos actualizados y una nueva actitud intelectual.

Alejandro Humboldt atribuyó en 1801 condiciones excepcionales a esta élite urbana como «...un mayor conocimiento de las relaciones políticas de las naciones y miras más extensas sobre el estado de las colonias y las metrópolis. La multiplicación de las comunicaciones con el comercio de Europa, y aquel mar de las Antillas que hemos descrito como un mediterráneo de muchas bocas, ha influido poderosamente en el progreso de la isla de Cuba y en las hermosas provincias de Venezuela; en ninguna parte de la América española ha tomado la civilización un aspecto más europeo» (2).

(1) Julio Le Riverend, "Conciencia de la contradicción", Santiago, n. ${ }^{\circ}$ 23, La Habana, 1976, pág. 171.

(2) Alejandro Humboldt, Ensayo Político sobre la isla de Cuba, tomo 1, Habana, 1930, pág. XLV.

R. I., 1996, n. 207 
En 1792 uno de los representantes de este grupo, el abogado Francisco Arango y Parreño, expuso en Madrid a nombre del cabildo habanero, los principios básicos de la nueva política económica a seguir en un documento más tarde ampliado y perfeccionado con otros artículos y memorias (3). La respuesta a sus solicitudes fue la creación de dos organismos para llevar a cabo el programa de transformaciones económicas y sociales, la Real Sociedad Económica de Amigos del País y el Real Consulado de La Habana, destinados a actuar como un cuerpo de consejeros, pero también dotados de recursos para el fomento de algunas obras de utilidad pública.

Los viajes y expediciones científicas, otro de lo medios propios de la Ilustración para promover proyectos económicos, también fue empleado como una vía institucional de canalizar las iniciativas de los hacendados habaneros. En 1794 la Corona autorizó el viaje de Arango a Inglaterra y Jamaica, la metrópoli de mayor progreso industrial y su colonia antillana, en busca de iniciativas y conocimientos aplicables en La Habana. Dos años después, el Conde de Jaruco y Mopox, propietario habanero influyente en la Corte, obtuvo concesiones y privilegios para financiar una expedición de reconocimiento en su país con amplios planes de desarrollo, la llamada Comisión Mopox.

\section{LOS NUEVOS PROBLEMAS}

En 1810 La Habana había llegado a duplicar su población en sólo tres décadas, alcanzando un total aproximado de 90.000 habitantes, donde los blancos pasaron a ser una minoría del $43 \%$. En las áreas rurales cultivadas se agrupaban cerca de 45.000 esclavos y unas 20.000 personas libres, lo que implicaba serios problemas de seguridad agravados por la dimensión que alcanzaba el territorio (4). A mediados del siglo xviII no pasa-

(3) Francisco ARANGo y PARREÑo, "Discurso sobre la agricultura de La Habana y medios de fomentarla», en Hortensia PICHARDo, Documentos para la Historia de Cuba, La Habana, 1977, pág. 162.

(4) Para estos cálculos y los siguientes:

Antonio VAlle HeRnándeZ, Suscinta Noticia de la situación presente en esta 
ban de 80 los pequeños ingenios localizados dentro de un cinturón de 20 a $24 \mathrm{~km}$ de radio en torno a la ciudad. Ahora se trataba de 400 ingenios y unos 50 cafetales dispersos por unos $6.289 \mathrm{~km}^{2}$, con distancias radiales máximas de $80 \mathrm{~km}$. La capacidad de producción de los ingenios había aumentado de un promedio de 43 a 136 ton. y, por tanto, también su tamaño y número de esclavos, haciendo necesaria una red de caminos para facilitar el transporte y el control del territorio.

Los ingenios se alejaban en busca de tierras fértiles y montes para el consumo de energía, chocando con las medidas de protección de la marina española sobre los árboles maderables con destino al Real Arsenal de La Habana. Una expansión territorial en ascenso comenzaba a avanzar a través de la Isla, de este a oeste, generando un proceso de poblamiento mucho más intenso y decisivo para la Isla que el primer proceso de poblamiento efectuado tres siglos antes desde oriente a occidente durante la conquista española. Pero este poblamiento, provocado por una rápida absolescencia o envejecimiento de los ingenios, por el agotamiento de los recursos naturales, había comenzado a causar alarma entre los hacendados pues en gran medida contribuía a debilitar su posición económica, tanto como la necesidad de renovar constantemente la mano de obra esclava:

«...en estos países no es dable esta riqueza si queda estacionaria, es preciso aumentarla día a día, o resignarse a verla desaparecer, y no puede ser de otro modo donde son perecederos los brazos cultivadores, donde los frutos exigen año a año nuevas tierras, donde las de mayor calidad no rinden producto pasado un cierto tiempo" (5).

Era necesario eliminar la trashumancia del ingenio y conjurar «...la preocupación fatal que hacen perecederas entre

colonia 1800, La Habana, 1977, págs. 74 y 75, y “Nota sobre la población de la Isla de Cuba", en Documentos que hasta ahora se compone el expediente que principiaron las Cortes..., Madrid, 1814, pág. 127.

Manuel Moreno Fraginals, El Ingenio, tomo 1, La Habana, 1978, pág. 68. Humboldt [2], págs. 103-107.

(5) ANC, Legajo 194/8679. Junta de Fomento.

\section{R. I., 1996, n. 207}


nosotros las fábricas que entre los extranjeros son eternas» (6), mejorando los métodos tradicionales de cultivo y elaboración del azúcar, de acuerdo al ejemplo de las colonias francesas e inglesas, basado en la mano de obra esclava y el perfeccionamiento de la tecnología.

Existía por tanto un encadenamiento de causas y efectos que obligaba a planear la acción territorial en secuencia, desde el nivel más elevado y general de los problemas del poblamiento rural y la colonización, hasta el funcionamiento interno de la misma plantación.

\section{El PLAN DE COLONIZACIÓN}

La estrategia trazada para equilibrar el poblamiento rural consistió en la distribución de pequeños núcleos agrourbanos de campesinos a través de la región cultivada con una alta concentración de esclavos, $\mathrm{y}$, por otra parte, en lograr una disminución del crecimiento excesivo de la capital y sus arrabales, creando con estos fines una estructura continua de poblados y caminos destinada a garantizar la seguridad, el transporte, y los servicios de abastecimiento $\mathrm{u}$ otro tipo requeridos por las plantaciones y por la propia cabecera regional. En líneas muy generales esta política pobladora había sido expuesta por Arango y Parreño en su programa de 1792, pero en lo concerniente a colonización rural las soluciones tradicionales se habían anticipado a los planes. Cuando en 1799 el Consulado dio forma teórica por vez primera este propósito en un plan apropiado, y propuso establecer una red de caseríos o aldeas extendidas por la región con un mínimo de veinte familias blancas procedentes de Canarias preparadas para sofocar sublevaciones en los campos (7), ya el proceso fundador había arrojado resultados similares obedeciendo a iniciativas aisladas. En realidad la propues-

(6) Memoria de D. Pedro Juan de Erice y Don Nicolás Calvo, CM Morales, tomo 79, Biblioteca Nacional «José Martí».

(7) Sobre colonias y fomento de la población blanca. ANC, Legajo 184/8330, Junta de Fomento. Además, el Real Consulado había sido autorizado por el artículo 23 de su real cédula de erección a ocuparse de la colonización rural y evitar el crecimiento de las ciudades grandes, entre otras. 
ta del Real Consulado sólo trataba de sistematizar o más bien optimizar experiencias anteriores.

Toda la jurisdicción de La Habana se hallaba repartida en haciendas mercedadas para la cría de ganado desde el siglo XVI. La expansión de los cultivos comerciales se llevó a cabo, por tanto, a iniciativa de sus propietarios, con la reconversión de estas haciendas ganaderas de amplios límites circulares en terrenos cultivados mediante la subdivisión en parcelas menores, proceso conocido como demolición de las haciendas. El poblamiento urbano del hinterland habanero se sustentó sobre estas iniciativas particulares o fundación de "colonias», bien distinta de la ocupación de terrenos vírgenes que dio origen a los primeros municipios de la Isla.

Al comenzar el siglo xVIII la demolición de los hatos y corrales permitió a algunos de sus propietarios o a los colonos que adquirían lotes en ellas, entregar pequeñas porciones, no mayores de 4 caballerías, para establecer una iglesia y repartir solares en torno. Varios de estos asientos de pobladores rurales fueron concebidos excepcionalmente como proyectos de ciertas pretensiones urbanas, a través de los cuales los fundadores reclamaron para sí títulos nobiliarios, pero en su mayoría surgieron como simples agrupaciones de casas, junto a ermitas rurales, que cohesionaban una población campesina dispersa ocupada casi siempre por el cultivo del tabaco.

En 1778 catorce nuevas poblaciones se agrupaban en los terrenos repartidos en derredor de la ciudad (8). A partir de entonces el establecimiento de núcleos agrourbanos se aceleró. Entre 1780 y 1810 aparecieron no menos de treinta poblados más en el interior de la jurisdicción habanera acompañando la expansión de ingenios y cafetales antes descrita. Este avance poblador se hizo más fácil en estos años con la división del territorio rural en 57 partidos y la autorización para establecer iglesias auxiliares a cuatro leguas $(20 \mathrm{kms})$ de distancia unas de otras.

Muchos de estos nuevos poblados alcanzaron cierta jerarquía como cabeceras de los partidos rurales o bien de las igle-

(8) Juan PÉRez DE LA RIVA, "Presentación de un censo ignorado: el padrón de 1778", Revista de la Biblioteca Nacional "José Marti", n.o 3, La Habana, 1977, pág. 5.

R. I., 1996, n. $^{\circ} 207$ 
sias auxiliares, más tarde convertidas en parroquias. La distancia entre los mismos oscilaba entre desde 4 a $20 \mathrm{~km}$ y muy raras veces sobrepasaban los 500 habitantes, pero su composición fue mayoritariamente blanca $(60 \%)$, en contraste con una capital donde los blancos habían pasado a ser minoría (9).

Este veloz movimiento de colonización rural no estuvo acompañado de una política coherente de emigración blanca, a pesar de la intensidad del mismo, comparable, dentro de sus dimensiones territoriales respectivas, con el experimentado en los Estados Unidos durante la expansión hacia el oeste. La emigración blanca hacia Cuba fue escasa e inestable, dependiente de hechos políticos externos, como la revolución haitiana y cesión de la Luisiana. Los españoles peninsulares emigrantes fueron pocos en este período, menos de 2.000, y se integraron al sector urbano dedicado al comercio en La Habana (10). Los provenientes de las islas Canarias, tradicionalmente campesinos, también cambiaron el destino hacia la capital (11). Los franceses refugiados de Haití se dispersaron por toda la región. Había menos de un millar en 1809 cuando se decretó su expulsión. Más de un centenar se dedicaban a ocupaciones relacionadas con la construcción (12). Desempeñaron un papel de extraordinaria importancia en la renovación de las plantaciones y en el trazado de caminos y puentes, con la protección de los hacendados y la Sociedad Económica (13).

Las migraciones internas y el crecimiento natural de la población, parecen haber tenido un gran peso en la distribución del poblamiento. Se ha afirmado que el crecido sector terciario de La Habana fue nutrido por el desplazamiento de los cultivadores de tabaco (vegueros) ante el avance de las plantaciones,

(9) Juan PÉRez DE LA RIVA, «Antonio del Valle Hernández ¿El primer demógrafo cubano?", Economía y Desarrollo, n. 29, La Habana, 1975, pág. 78.

(10) Pablo TORNERo, «Emigración, población y esclavitud en Cuba (1765-1817)", Anuario de Estudios Americanos, v. XLIV, Sevilla, 1987, págs. 229-280.

(11) Expediente promovido por el gobernador ante el Consejo de Indias, CM Morales, tomo 79, n. ${ }^{\circ}$ 30, Biblioteca Nacional "José Martí",

(12) Alain YACOU, L'emigration a Cuba des colons francais au cours de la revolutions, These de Doctorat de III ${ }^{e}$ Cycle, Biblioteca Nacional «José Martí», págs. 227 y 225.

(13) Manuel Moreno Fraginals, [4], pág. 72. 
o por libertos que acudían a la ciudad en busca de oportunidades de vida (14). La movilidad de hombres blancos o negros en los partidos rurales trataba de ser regulada con el establecimiento de licencias para trasladarse de uno a otro. La lucha contra la vagancia fue una preocupación esencial para la clase dominante a partir de estos años, al contemplar con asombro el notable crecimiento de los arrabales extramuros, pero sin lograr encontrar solución para dar impulso a un movimiento de hombres libres hacia las tareas del campo.

No obstante, la ausencia de un plan expresamente preconcebido de colonización rural, algunas de las iniciativas fundacionales, aunque descansaron en modos de poblar tradicionales ya experimentados, constituyeron esfuerzos significativos por variar el contenido de sus propósitos y movilizar recursos humanos de acuerdo a las necesidades planteadas.

En 1802 tras producirse un gran incendio en los populosos arrabales habaneros, fue dictada la prohibición de reedificar en ellos por razones de protección militar (15). La Sociedad Económica encontró entonces la ansiada ocasión de «...no permitir crecer a la capital y animar las ocupaciones del campo, trasladando a las familias honradas a formar nuevas poblaciones o aumentar las principiadas...» (16). Con este fin adquirió 100 caballerías en la hacienda San Marcos, en el extremo occidental de la zona cultivada, para repartirlas entre las familias blancas afectadas y ceder 4 para fundar la población de San Marcos de Artemisa (17). La fundación de Artemisa tomaba el significado de un proyecto ejemplar animado por el espíritu de la ilustración habanera, pues se trataba de la disolución de un vínculo, modo de tenencia de la tierra en "manos muertas» que había establecido en la hacienda mucho antes la propia

(14) Pérez de la Riva, [9], pág. 21 y Moreno Fraginals [4], pág. 298.

(15) La sospecha de haber sido una acción de saneamiento sobre el conflictivo barrio de Jesús María, sito donde comenzó el incendio, con el fin de expulsar su población, compuesta en gran medida por grupos muy pobres de negros y mulatos libres, no ha dejado de ser advertida. Ver Juan CHAILLOUX CARDONA, Sintesis histórica de la vivienda popular, La Habana, 1945, pág. 45.

(16) Colección facticia de Vidal y Morales, v. XX, n.o 38, Biblioteca Nacional «José Martí».

(17) ANC. Sobre traslación al campo de familias blancas. Legajo 184/8327, Junta de Fomento.

R. I., 1996, n.o 207 
familia del prior de la Sociedad, Arango y Parreño, dando paso así a formas dinámicas de colonización agraria. Entre 1803 y 1807 quedó establecida la población que progresó con lentitud, demostrando la dificultad de cambiar pobladores urbanos en rurales.

La llegada de los emigrados franceses permitió al Marqués de Cárdenas activar la fundación de la ciudad de señorío de San Antonio de los Baños, iniciada desde 1784, y convertirla en centro de los refugiados, desde donde impulsarían la difusión las plantaciones de café, y también en pueblo de temporadas o de recreación con sus baños de río. Tuvo un éxito notable: en 1804 había vendido 214 solares (18).

La región habanera, rica en aguas medicinales, era propicia para el aprovechamiento de estos recursos para mejorar la salud, circunstancia que cobraba relieve dentro de un nuevo comportamiento hacia la naturaleza y el conocimiento científico, favoreciendo el hábito de recreo y la distracción campestre. Algunas poblaciones debieron su existencia en gran parte a este papel de pueblos de baños. La fundación del pueblo de Madruga, por iniciativa de los vecinos de la hacienda, se debió a la atracción de sus baños medicinales (19). Años antes la ciudad de señorío de Santa María del Rosario, a cinco leguas de La Habana, fue revitalizada por el Conde de Casa Bayona gracias al descubrimiento de aguas termales.

El cultivo de la caña y el café avanzaba a través de la región demoliendo hatos y corrales y penetrando en la fértil llanura de tierras rojas al sur de La Habana, regada por el río Mayabeque, el más caudaloso de la jurisdicción, y allí también alteró el rumbo de otro proyecto urbano. En 1775 cerca de 200 familias de vegueros habían solicitado transformar el caserío de San Ju-

(18) Francisco PéRez de la RIVA, "Los señoríos cubanos», Revista Bimestre Cubana, vol. LVII, n.o 2, La Habana, 1946, pág. 97.

(19) Decripción del pueblo y partido de Madruga, CM Bachiller, n.o 819,' Biblioteca Nacional «José Martí». 
lián de los Güines en villa, pero las condiciones exigidas por el ingeniero militar Luis Huet, no menos de 80 caballerías expropiadas para tierras comunales y de propios, detuvo la gestión. En 1791, uno de los hacendados azucareros más capaces, Nicolás Calvo, fue designado por el gobernador Luis de las Casas para hacerse cargo del proyecto con la intención de fomentar ingenios azucareros en aquella llanura de regadío natural. En 1815, la villa de Güines era uno de los mayores pueblos de la región con casi 2.000 habitantes y la cabecera del partido azucarero más productivo.

El aprovechamiento de los vegueros desplazados de sus tierras por las plantaciones constituyó el objetivo del señorío fundado por el Conde de Jaruco y Mopox en sus haciendas al este de Güines en 1802. Autorizado a pagar a la Corona las deudas de su expedición con tabaco molido repartió 220 caballerías y separó 10 para la ciudad de Nueva Paz. En 1806 se comenzó a construir el templo, ya arraigadas las familias, del que sería el último de los señoríos cubanos antes de ser revocados por decretos de 1813 en todos los territorios de España.

La expansión del azúcar al este de La Habana, en dirección a la "Vueltabajo» de la Isla, trajo como consecuencia la aparición de otro núcleo urbano que, como el pueblo de Güines al sur, concentró la actividad comercial y residencial de su partido. El pueblo de Guanajay, surgido hacia 1786 sobre un grupo de solares repartidos a renta a favor del sostenimiento de una vieja iglesia, terminó por transformarse en uno de los más prósperos del hinterland habanero, rodeado de ingenios y cafetales. La condesa de Gibacoa, dueña del terreno, fue su protectora y contribuyó a su fomento velando por la disciplina y el orden del asentamiento y el aumento de su población (20).

El tenaz esfuerzo por la colonización interna de la región habanera representado por este despliegue de pueblos aparecidos a distancias promedios de $15 \mathrm{kms}$ unos de otros, no era suficiente para asegurar el futuro de la plantación esclavista. Desde muy temprano se tuvo consciencia de la necesidad de contemplar un plan de desarrollo mucho más amplio y con mayor alcance estratégico dirigido a poblar las principales bahías de Cuba, sobre todo aquellas que desempeñaban un papel de fron-

(20) ANC, Legajo 475/9, Escribanía de Gobierno. 
tera en la parte oriental frente a Haití y Jamaica, temidas como «funestas bocas» de penetración del enemigo, fuera negro o inglés. También se valoraba su posible desarrollo futuro como enclave de plantaciones, como regiones de una explotación a largo plazo.

El conde de Jaruco se adelantó en este sentido a las gestiones de la Sociedad Económica que sólo había considerado muy someramente este aspecto y la Comisión Mopox tomó a su cargo el estudio de este ambicioso propósito de poblamiento costero. Dotada de ingenieros, botánicos y dibujantes, llevó a cabo desde 1797 el reconocimiento de las bahías de Jagua (Cienfuegos), Guatánamo, Nipe, Nuevitas, Mariel, Cabañas y Bahía Honda, con planos y memorias sobre sus recursos (21). En 1802 la Comisión cesó su trabajo por falta de fondos, pero la defensa costera de La Habana había logrado resultados de menor escala al margen de sus planes, gracias a la iniciativa de los hacendados que financiaron en la costa norte de la región cultivada, al este y al oeste de la capital, la construcción de ocho torreones circulares en las desembocaduras y bahías por donde se extraía el azúcar de los ingenios cercanos con destino a los muelles habaneros (22). La única población costera establecida entonces fue Manzanillo, planeada desde 1792 en el acceso a la cuenca del río Cauto, en la costa sur del oriente de la Isla, y fundada con recursos locales y por decisión del gobierno superior entre 1797 y 1802, para detener el contrabando de madera con los ingleses de Jamaica (23). El

(21) Uno de los autores que han estudiado esta Comisión la considera más bien encaminada a la realización de proyectos y estudios que a su ejecución, Ángel GUIRAO DE VIERNA, "El proyecto cubano del Conde de Mopox: aspectos generales de su organización y financiación", Cuba Ilustrada. La Real Comisión de Guantánamo. 1796-1802, Madrid, 1992, tomo I, págs. 17-41.

(22) El capitán de la Armada, Juan de Araoz, diseñó dos tipos de torreones circulares para la defensa del tráfico costanero, Legajo 163, Junta de Fomento, Archivo Nacional. Sobre el plan general: «Los torreones de La Habana: azúcar y defensa en el siglo XviII cubano», Boletín de Historia Militar, n. ${ }^{\circ}$, La Habana, 1944, pág. 33 y Antonio TRAmos ZÚÑIGA, «La fortificación española en Cuba, Siglos XVI-XIX", Atrio, n.o 5, 1993, pág. 54.

(23) ANC. La Comisión Mopox incluyó la rada de Manzanillo entre sus planes pero no llegó a realizar proyecto alguno. Legajo 509/26299, Gobierno General. 
poblamiento de los puertos debió esperar por la promulgación de la Ley de Población Blanca en 1817, cuando la supresión de la trata legal de esclavos hizo pensar más seriamente en la emigración de hombres libres (24).

\section{LOS CAMINOS Y LA CONTINUIDAD ENTRE CIUDAD Y REGIÓN}

La gestión encaminada a articular las comunicaciones entre los nuevos poblados, las plantaciones y la capital a través de una red de caminos eficientes nació con el programa de la Sociedad Económica. La construcción de caminos disminuía el extenso territorio "...donde se hallan fundadas varias villas y ciudades y las principales haciendas de azúcar, cuya directa comunicación ha de ser con ella que es la capital, el centro de su comercio y el puerto de sus importaciones y exportaciones, todos esos lugares poblados no subsisten, sino por sus relaciones con La Habana y a medida que crezca su comunicación con ésta, recibirán un mayor fomento, ventajosos a ellos mismos, a la ciudad y al Estado» (25).

La estrecha relación entre la ciudad y su región hizo concebir el plan de caminos como una estructura continua desde los barrios de extramuros hasta los límites de la región cultivada dirigida tanto a encaminar el transporte como a equilibrar el poblamiento:

«Con los buenos caminos se fomentará la población de los campos y no sólo se evitará que sus moradores se pasen a serlo de ciudades grandes, sino que muchos de los de éstas se dedicarán a la agricultura. Cuando hay un camino bueno se piensa aunque se viva en el campo, que está uno viviendo en la ciudad, porque el camino parece continuación de una de las calles» (26).

(24) Consuelo Naranjo Orovio, «Fomento y Organización del territorio: un proyecto perdurable del Conde de Mopox y Jaruco", Cuba ilustrada..., [21], págs. 53-75.

(25) ANC, Legajo 115/4843, Junta de Fomento.

(26) Op. cit... [6].

R. I., 1996, n. 207 
A partir de 1796 se acometió la construcción de 100 leguas de caminos y puentes siguiendo las cuatro direcciones radiales principales desde la ciudad: hacia el este y hacia el oeste, y otras dos hacia el sur. Estos caminos que se extenderían por una zona de 20 leguas alrededor de la capital, comenzaban a fusionarse al confluir en ella y, de vías de ocho varas de ancho se transformaban en calzadas de quince o dieciséis, capaces de asimilar todo el tránsito. Por tanto el plan de caminos y calzadas se inició a modo de ensayo con el mejoramiento de un tramo de calzada inmediato a la ciudad, entre la esquina de Tejas y el puente de Chávez, donde convergía todo el tráfico desde los campos. El Real Consulado lo realizó en varios meses con el trabajo de negros cimarrones y a un costo de 30.000 pesos (27). La experiencia demostraría que tal plan era demasiado costoso e irrealizable. En 1816 se había reducido a tres ramales principales y de éstos sólo se había terminado el que conducía a la villa de Güines, centro del crecimiento azucarero. Las calzadas urbanas se habían extendido hasta dos leguas de las murallas, enlazando los barrios o arrabales.

A pesar de esto, la integración de las poblaciones con los caminos reales, sea cual fuera la calidad de éstos, caracterizó la región habanera como un elemento de identidad y de continuidad entre la capital y sus poblaciones. La mayoría de sus pueblos son pueblos de caminos o encrucijadas, donde una calle ancha o real viene a ser un fragmento ampliado del camino real y concentra las actividades principales; la plaza de la iglesia muchas veces no es más que un accidente colateral dentro de una urbanización esencialmente lineal.

La política urbana desarrollada en estas poblaciones no estableció criterios normativos. La única legislación vigente en esta materia era la Recopilación de Indias, susceptible de ser interpretada con una flexibilidad tal que diera lugar a una variada gama de soluciones.

Las villas y ciudades, nacidas con pretensiones más jerárquicas, se vieron obligadas a establecer relaciones con la legislación indiana, pero los numerosos caseríos y aldeas se estructuraron con mucha libertad, variando las dimensiones de sus es-

(27) ANC, Legajo 258/1, Asuntos Políticos. 
pacios públicos y obedeciendo a las condiciones del terreno y la trayectoria de los caminos. Su crecimiento y diseño quedaba en manos de los capitanes de partido o de los sacerdotes que cobraban las rentas de las parcelas y que actuaban con una gran espontaneidad.

Los casos más ambiciosos y excepcionalmente expresivos en el terreno de las formas urbanas coincidieron casi siempre con poblaciones de mayor rango, previamente planteadas. Uno de éstos, en donde el ordenamiento vial se convirtió en motivo de referencia culta, tuvo lugar en la ciudad de San Antonio de los Baños, donde la calle real, más ancha que todas, se convirtió en un eje que enlazaba la plaza del cabildo y del "palacio» del marqués, de ángulos cerrados, con la plaza de la iglesia, hasta detener su perspectiva sobre la fachada de esta última. Fue el único caso en que un monumento arquitectónico se convirtió en motivo final o punto de fuga de un trazado coordinado de eje central y plazas, recurso derivado del urbanismo barroco. Otra aplicación semejante en cuanto a filiación formal fue el plano de planta pentagonal propuesto por el Conde de Jaruco para levantar su ciudad de Nueva Paz y rechazado por el Consejo de Indias por no ajustarse a sus leyes. El Conde pretendía fabricar con auxilio del arquitecto francés, Jerónimo de Merlié, que había dibujado el plano de Nueva Paz, casas más sólidas y confortables para sus pobladores que los ranchos levantados en otros señoríos anteriores al suyo.

En ambos casos se trataba de situaciones extraordinarias muy ligadas a la experiencia personal de los fundadores, nobles en contacto con la corte española y conocedores de las colonizaciones que la monarquía española había emprendido en Andalucía con formas urbanas semejantes desde el reinado de Carlos III. Las ciudades delineadas por los participantes en la Comisión Mopox también reprodujeron en sus planos esquemas ideales inspirados en los reglamentos de las alcudias carolinas. Por otra parte, la evolución hacia costumbres más aristocráticas entre los hacendados introducía un hábito patriarcal en estos poblados habaneros y los convertía en ocasiones en sitios de temporada o residencia cercana a sus plantaciones, lo que les atraía obras de una inesperada distinción urbana, bien fuera una lujosa vivienda, o la edificación de algún destacado templo. Otras veces fueron los propios vecinos con 
su esfuerzo colectivo quienes edificaron nuevos templos $\mathrm{y}$ otras obras de utilidad social.

La tendencia hacia el ordenamiento geométrico de los poblados con la aplicación de un trazado en cuadrícula perfeccionado, sólo logrado antes en casos muy aislados en las cercanías de la capital, se incrementó con las poblaciones de Artemisa, Madruga y Guanajay, delineadas por algunos de los más experimentados agrimensores públicos.

La solución más trascendente y generalizada en cuanto al orden de las poblaciones se llevó a cabo en Güines a partir de 1792. El proyecto inicial del ingeniero Huet se organizaba en torno a una plaza central, de grandes dimensiones y rodeada de portales, evidentemente inspirada en el modelo indiano, pero la intervención posterior de Nicolás Calvo extendió el uso de estos portales a todas las calles del pueblo, con un ancho de cuatro varas, «...para la gente de a pie, de suerte que ni el sol moleste, ni las lluvias impidiesen los oficios y agradables ratos de la sociedad» (28). Este uso civilista del portal, tal vez proveniente de la experiencia de las plazas habaneras, o de sus calzadas, lo hizo inseparable en lo adelante de las calles de muchas poblaciones nuevas, fundadas en el transcurso del siglo XIX en Cuba, originando la manzana-isla, rodeada de galerías por sus cuatro frentes y en su interior las viviendas en serie, el motivo urbano más recurrente desde entonces en los pueblos de nueva planta de la Isla. Muchos de ellos fueron como Güines, pueblos de llanuras, donde las calles, inundadas por las lluvias o castigadas por el sol, hicieron del portal refugio indispensable para la vida cotidiana, y durante las noches, el sitio de relación social de las familias.

Pero la importancia de la infraestructura vial no fue sólo un hecho de poblaciones y de carreteras dentro de la región. La plantación en sí misma se organizaba en torno a un sistema de caminos jerarquizados que separaban los campos de cañas y buscaban las ventajas del emplazamiento para trazar las «guardarrayas maestras" o los caminos transversales que acortaban la conducción de las carretas hacia el molino. Existió por tanto una obra vial hoy irrecuperable que los emigrantes franceses

(28) ANC, Legajo 700/1, Escribanía de Galletti. 
matizaron con referencias cultas tomadas del jardín cortesano, trazando rotondas y sendas bordeadas de palmas, limoneros y árboles frutales para el uso del ingenio que proporcionaban un inusitado aspecto de disfrute bucólico a la prolongada residencia del propietario en su ingenio o cafetal.

La aspiración culminante en materia de comunicación regional fue el proyecto de un canal navegable planteado en la Real Sociedad desde 1795 . Se trataba entonces de retomar una vieja idea que databa de 1743, cuando el Real Arsenal pretendió utilizar una vía de agua para la explotación de una reserva forestal calculada en 80.000 árboles de los montes de Güines. En 1767 fue replanteado nuevamente el canal, pero ya los montes se hallaban en disminución creciente. Ahora resurgía en el seno de la Sociedad con un contenido más complejo, como una vía de navegación para extraer el azúcar, como medio de regadío y fuente de energía para mover los molinos de caña. Al enlazar las dos costas de la Isla el proyectado canal adquiría una trascendencia estratégica que no podía pasar inadvertida para los planes de desarrollo regional de largo alcance que la Comisión del Conde de Jaruco y Mopox se proponía encauzar. Con evidente contrariedad los miembros de la Sociedad Económica contemplaron cómo el canal había sido incluido entre las tareas de la Comisión con la aprobación real, y se le confiaba a dos ingenieros militares pertenecientes a la guarnición habanera, los hermanos Félix y Francisco Lemaur, e incorporados a la expedición del conde por su reconocida experiencia en obras hidráulicas (29).

En 1798, los ingenieros iniciaron un minucioso reconocimiento de la región habanera que los llevó a desechar por impracticable la primitiva idea sobre el canal, que consistía en unir las aguas de los dos ríos más caudalosos y perennes de la región, el río de Mayabeque o de los Güines y el de Almenda-

(29) Hijos del ingeniero francés Carlos de Lemaur, llamado a España por el Marqués de la Ensenada para realizar obras hidráulicas y caminos, en algunas de las cuales participaron con su padre, como en el canal navegable desde Guadarrama hasta Las Rozas. En La Habana colaboraron con la Real Sociedad Económica en proyectos de maquinarias, traducciones de textos, caminos, muelles..., etc., y se tenían por herederos de los conocimientos y experiencias de su padre. Su presencia en la ciudad puede tomarse como una consecuencia de esto último.

\section{R. I., 1996, n.o 207}




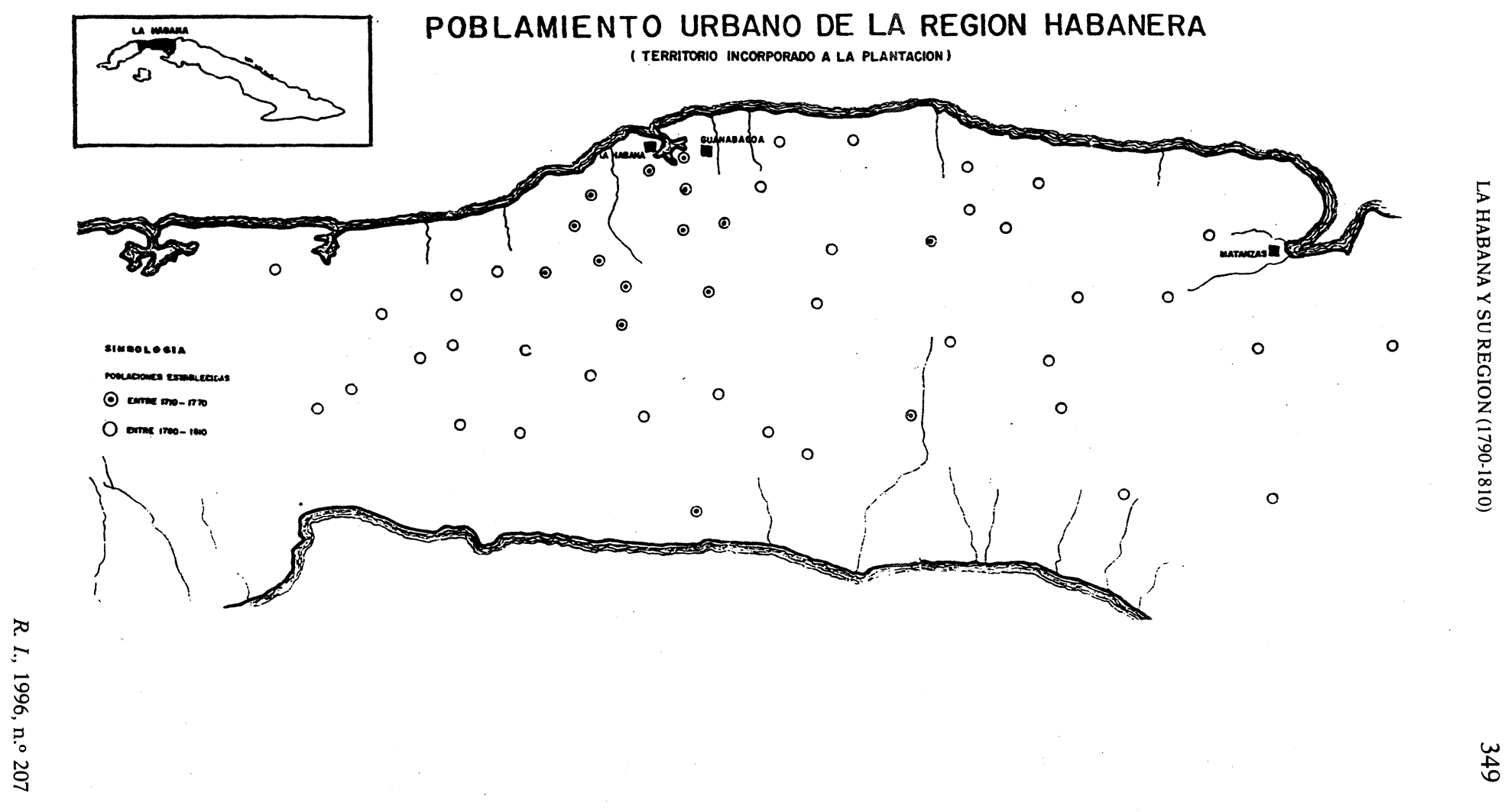


res. A cambio propusieron un nuevo canal de 19 leguas y con 40 esclusas entre el puerto de Batabanó al sur y La Habana al norte, alimentado por una presa situada a medio camino entre los dos puertos, en las elevaciones de Bejucal, permitiendo de ese modo la navegación entre ambas costas de la Isla y un acceso más fácil al puerto habanero desde el sur. Desde allí el canal se dirigía hacia Güines, utilizando las aguas del río, con posibilidades de ser extendido luego hacia el este, en busca de la bahía de Jagua, donde los mismos ingenieros habían planeado pocos meses antes una ciudad entre las tareas asignadas a la Comisión.

Un canal de tal magnitud se ajustaba a los amplios propósitos del conde de Jaruco. Al enlazar las dos costas de la región habanera, el proyecto ganaba en importancia estratégica, pues enlazaba dos ámbitos de la navegación americana, el mar Caribe y el Golfo de México, eliminaba el peligroso paso por el estrecho entre Yucatán y Cuba y convertía a La Habana en la receptora de casi toda la navegación costera insular y de una gran parte de Suramérica, capaz de ser abastecida desde otras regiones distantes, aún en caso que su jurisdicción viera agotada su riqueza agrícola. Por otra parte, la vía de agua habilitaba el regadío de 16.000 caballerías de tierra cultivable a su largo.

Calculado su costo en un millón de pesos, no pasó de ser más que un conjunto de planos, algunos sin pasar en limpio al cese de la Comisión Mopox en 1802. Quedaba latente la necesidad de expansión de la industria azucarera a través de la Isla incorporando nuevos territorios, más fértiles y baratos, la cual no sería de todo satisfecha hasta la aparición de un nuevo medio de comunicación, el ferrocarril, que en 1837 seguiría una trayectoria semejante con rápido éxito (30).

Tanto el proyecto de canal como la subdivisión de las haciendas y los planes de caminos, fueron sedimentando una obra cartográfica considerable en la región. La vista en perspectiva aérea del tramo de jurisdicción recorrido por el canal, dibujada de modo excelente por los Lemaur, constituyó un hito

(30) Dolores GonZÁlez-RIPOLL, "Instituciones y proyectos ilustrados en Cuba a fines del siglo XVIII", [21], págs. 43-51, y Miguel Ángel PUIG-SAMPER, "La exploración científica en Cuba en el siglo XVIII", Arbor, n. ${ }^{\text {os }}$ 547-548, t. CXXXIX, Madrid, CSIC, 1991, págs. 55-82.

R. I., 1996, n.o 207 
insuperable. La acumulación de planos de haciendas realizados por los agrimensores durante décadas permitió la confección de un mapa de la región con sus hatos y corrales circulares que servía de útil instrumento desde 1784. El conocimiento de los límites de los partidos y su adecuación de las divisiones de las parroquias, esencial para viabilizar el cobro de los diezmos, movió al obispado a rectificar los planos existentes, corrigiendo la dirección de los ríos, la posición de las montañas y, sobre todo la distancia entre los nuevos pueblos, pues se acortaron los límites entre las parroquias hasta dejar establecidas 50 de ellas (31). Sin embargo, siempre consciente de tener bien actualizada la representación del territorio dedicado al cultivo, el Real Consulado se propuso ejecutar un plano de extraordinario alcance y exactitud que resumiera todo el conocimiento acumulado hasta el momento. En octubre de 1805 se había concluido la obra a un costo de 11.520 pesos y abarcaba un espacio de $719 \mathrm{~km}^{2}$, mucho menor que lo esperado, pero suficiente para hacer constar con orgullo que no existía «...en toda la extensión de los territorios de España una porción de país representada en plano tan exacto» (32).

\section{LA BÚSQUEDA DE NUEVAS FUENTES DE ENERGÍA}

Los esfuerzos de los hacendados habaneros por transformar sus ingenios se encaminaron a hacerlos eficientes y estables, dotados de regadíos, trenes de calderas de un sólo fuego y molinos movidos por una fuente de energía constante. El ingenio de "nueva planta» que la Sociedad Económica se propuso difundir con un sistema de premios, encerraba una aspiración de autosuficiencia y perfección que descansaba en el aprovechamiento de una tecnología actualizada: suelos fertilizados por el agua, con independencia del régimen de lluvias, calderas alimentadas con el fuego del bagazo de caña de la propia plantación, molinos movidos sin el empleo de la fuerza de tracción animal torpe, lenta y consumidora de pastos (33). 152.

(31) «El Obispo Espada», Revista de Cuba, tomo XI, La Habana, 1882, pág.

(32) ANC, Legajo 184/8325, Junta de Fomento.

(33) ANC, Legajo 101/4330, Junta de Fomento. 
Se trataba de elaborar un modelo de ingenio racional opuesto a una realidad de atraso y ruina. El escenario de los ensayos más importantes tuvo lugar en la llanura de Güines, donde existían condiciones naturales inmejorables y donde los vegueros habían abierto seis zanjas para regar el tabaco.

«A las ventajas inapreciables del regadío -afirmaba en 1797 Nicolás Calvo-, agréguese la de moler las cañas con trapiche de agua y la gran fertilidad con que las produce aquel terreno de Güines. Allí pues preparó la naturaleza cuanto España podía apetecer para llegar a conseguir que la mayor parte del azúcar que en la Europa se consumiese, fuese producto de un territorio español» (34).

Desde 1796 comenzaron a construirse allí algunos ingenios dotados de regadío y molinos hidráulicos bajo la dirección de los emigrados franceses, especialmente de Julián Lardiere, traído desde Jamaica por los hacendados, donde había administrado las plantaciones del conde de Courtines. Al mismo tiempo que se concebía el canal de navegación, un grupo selecto de hacendados establecieron cinco ingenios de este tipo: "Nueva Holanda" de Nicolás Calvo, "La Ninfa» de Arango y Parreño, "Suriñam» del conde de Casa Montalvo, "Alejandría» del conde de O'Reilly, y «Amistad» del gobernador Luis de las Casas (35).

Fue abierta una nueva zanja a un costo de 25.000 pesos y el consumo del agua del río tomó un carácter de oposición entre los campesinos y los hacendados. El francés Andrés Bailly, experto en regadíos, determinó que el caudal del río era de $3.169 \mathrm{~m}^{3}$ por segundo, regaba cerca de 1.172 caballerías y los in-

(34) Sobre el entredicho puesto por la Real Factoría de Tabacos a las tierras de la vega de Güines, ANC Junta de Fomento, Leg. 85/3489.

(35) Los ingenios de agua casi al mismo tiempo que se iniciaba el reconocimiento del terreno para el canal por la Comisión Mopox, en cierta forma se puede interpretar esta circunstancia como una iniciativa paralela tomada por los miembros del Consulado para llevar a cabo sus propios planes hidráulicos al quedar desplazados del proyectado canal. De hecho el caudal del río Mayabeque disminuyó al punto de dudarse de la posibilidad de alimentar el canal de navegación y riego.

\section{R. I., 1996, n.o 207}


genios de agua consumían la cuarta parte del total (36). Pero esta actividad en torno a las posibilidades de empleo del agua en los ingenios, terminaría por convertirse en un camino cerrado al quedar abandonada la idea del canal de navegación y riego, pues fuera de Güines no se encontraban condiciones semejantes en el resto de la jurisdicción habanera, donde las corrientes de agua eran cortas y mucho más pobres. Aparte de los ingenios mencionados sólo uno más se instaló con molino de agua, el ingenio "Nueva Vizcaya» por la casa comercial vasca de Cantera y Zabaleta, junto al río Canasí.

La busqueda de una nueva fuerza motriz estuvo encaminada por esa evidente razón en otros sentidos desde muy temprano. El más trascendente fue el empleo del vapor. En 1794, el conde de Casa Montalvo, acompañante de Arango en el viaje a Inglaterra, mandó construir en Londres el diseño de un molino de vapor realizado por Agustín de Betancourt, director del Real Gabinete de Máquinas de Madrid (37). Dos años después llegó a La Habana la «bomba de fuego", cuando su promotor ya había fallecido, y fue instalada por su yerno, el conde de Jaruco en el ingenio Siebabo, cercano a Güines, donde trabajó por breve tiempo sin éxito debido al uso de trapiches inadecuados (38). Pero esta experiencia dejaba abierta una perspectiva válida: en 1823 sólo permanecían los cinco ingenios hidráulicos iniciales en lås 1.230 caballerías regadas en Güines, pero ya se empleaban cuatro máquinas de vapor (39). El propio Montalvo también dio curso a otro ensayo para reactivar un viejo ingenio cercano a La Habana, reconstruyéndolo a la manera de los franceses para demostrar la posibilidad de reutilizar terrenos considerados agotados y abandonados por el cultivo cañero. 91.

(36) J. A. Cosculluela, El regadio en el valle de Güines, Habana, 1914, pág.

(37) Betancourt fue uno de los hombres de ciencia más destacados de la Ilustración española. Estudió por encargo de la monarquía española los adelantos científicos que tenían lugar en Inglaterra y Francia. Arango y Parreño y el Conde de Jaruco intentaron traerlo a Cuba para dirigir los planes de caminos e instalación de nuevas maquinarias sin lograrlo. Ramón GuTIÉRREZ y Cristina EsTERAS, Territorio y Fortificación, Madrid, 1991, pág. 80.

(38) MoReno Fraginals [4], pág. 87.

(39) ANC, Legajo 875/29547, Gobierno Superior Civil. 
El uso del viento para mover los molinos, al modo de Jamaica y otras Antillas, trató de ser implantado por el hacendado Pedro Diago en su ingenio Cumbre de 1800, con un trapiche diseñado por el francés Jerónimo Merlié para ser situado sobre una elevación, pero el inconstante régimen de vientos de la Isla llevó al fracaso el intento (40).

Con estas experiencias los hacendados azucareros agotaron las posibilidades a su alcance para transformar sus plantaciones y dejaron introducidas en la práctica una serie de iniciativas que con lentitud se implantarían en las décadas siguientes. Los resultados quedaron planteados en unos cuantos ingenios excepcionales que a modo de ejemplos trataron de estimular un cambio de actitud en los demás propietarios.

\section{LAS NUEVAS INSTITUCIONES Y SUS EFECTOS URBANOS}

Mientras se debatían los problemas regionales engendrados por el crecimiento azucarero y cafetalero, la ciudad cabecera era objeto de atención. Desde 1792, cuando Arango y Parreño elevaba a la Corte sus primeras peticiones, el prebístero Agustín Caballero, reformador del pensamiento filosófico, analizaba con profundidad los problemas urbanos desde las páginas del períodico recién fundado en la ciudad (41). Diferencias sociales y de origen separaban a sus habitantes. La clase dominante se encontraba escindida en hacendados y comerciantes, los primeros casi siempre criollos y los segundos, peninsulares. Esta división los hacía incapaces de emprender una acción unitaria para llevar a cabo obras de utilidad pública: los comerciantes «...no sacrifican nada a favor de un país que miran como extraño y sólo tratan de esquilmar» (42). Entre la clase media y pobre, en su mayoría ocupada en actividades terciarias o dependientes del consumo, los emigrantes españoles dominaban el sector comercial interno; los negros y mulatos libres, los oficios artesanales más numerosos; los blancos criollos, cerrados en una

(40) ANC, Legajo 93/3943, Junta de Fomento.

(41) "Consideraciones del medio filósofo sobre La Habana» Papel Periódico de la Habana, n.o 41 a 46, La Habana, mayo a junio de 1792.

(42) Idem.

R. I., 1996, n.o 207 
mentalidad que despreciaba por igual el ejercicio del comercio y los oficios de los negros, se encontraban expuestos a la desocupación con su secuela de riesgos sociales.

Ante tal situación el proyecto urbano ilustrado de los hàcendados habaneros asumió un carácter de saneamiento social con medidas tendentes a mejorar los servicios y la higiene pública, la educación, a establecer el orden y la disciplina en las actividades urbanas, y estuvo acompañado de los primeros signos de novedad y en el terreno de la arquitectura. Un clima de progreso se enfrentaba a la tradición y a las costumbres populares.

La primera obra de importancia que puso de relieve el sentido de esta tendencia urbana fue la reforma de la Casa de Beneficencia. En 1792 un grupo de acaudalados vecinos se propuso reedificarla en extramuros y ampliarla con el apoyo entusiasta del gobernador. Estos vecinos «...lastimados de ver sus calles sembradas de mendigos (...) de huérfanos abandonados (...) anhelando la erección de un oficio (...) y al tierno huérfano la educación conducente para ser útil a la república y a sí mismo...» (43), recaudaron 109.575 pesos para levantar un nuevo edificio, con un monumental proyecto concluido parcialmente e inaugurado en 1794 para acoger niñas (los varones al completarse la obra en 1827), a cargo de la Sociedad Económica. La tradiciónal donación piadosa se desprendía de la Iglesia y pasaba a manos laicas, adquiriendo matices muy prácticos. La Casa acogió niñas pobres o abandonadas y mujeres indigentes que junto con un grupo de esclavas garantizaron su sostenimiento con obras de tejidos, bordados y torciendo tabacos para la Real Factoría (44).

El establecimiento de escuelas de náutica, matemáticas, química y un jardín botánico, estuvieron entre las primeras consideraciones del Real Consulado, inicialmente con intentos aislados, luego tomaron cuerpo en la propuesta de un instituto de Ciencias Exactás y Naturales, elevada en 1797 al Príncipe de la Paz. Dotada Cuba «...de una población blanca mucho más considerable que cualquiera de las colonias de América merece con-

(43) ANC, Legajo 392/14850, Gobierno Superior Civil.

(44) ANC, Legajo 861/29139, Gobierno Superior Civil. 
cesión para que los hijos de familia que no pueden ir a España, estudien aquí las ciencias que se aplicarán a la agricultura y la navegación, bases de nuestra riqueza» (45).

La finalidad perseguida no era sólo proporcionar empleo a los blancos, sino lograr un estado de independencia económica con el desarrollo de una marina propia y hombres capacitados en maquinarias y fabricación de azúcar. El instituto, planeado por Arango y Nicolás Calvo, se inspiraba en el que había abierto poco antes en Asturias Gaspar de Jovellanos, quien había enviado a solicitud de ellos un programa del plan de estudios. La respuesta de Godoy fue dilatoria: declinar la tarea hacia la Comisión Mopox (46).

Muy unido al tema de la química, de la salud y de la agricultura estaba el jardín botánico. En 1794 se discutía en la Sociedad su posible apertura cerca de la Beneficencia y un año después al arribar Martín Sessé, director del Jardín Botánico de México, al frente de la Real Expedición Botánica de Nueva España, se replanteaba y quedaba pendiente de la preparación de un discípulo para su atención (47). Tres años más tarde, Sessé envió un plano del jardín mexicano para que sirviera de modelo, pero la apertura del mismo se dilataría aún por casi dos décadas.

Las aspiraciones de la Sociedad Económica en cuanto a educación no encontraron apoyo alguno, exceptuando la escuela náutica fundada en el pueblo de Regla, hasta la llegada en 1802 del nuevo obispo Diego de Espada y Landa, de origen vasco y educado en el ambiente de la Ilustración española,

(45) ANC, Legajo 179/8213, Junta de Fomento.

(46) El proyecto ha sido calificado como «...un ensueño costoso que las autoridades españolas, ciertamente, no estaban dispuestas a considerar todavía, Renate SIMPSON, La Educación Superior en Cuba bajo el colonialismo espanol, La Habana, 1984, pág. 128, ver también Pedro M. PRUNA, "Los inicios del movimiento científico en Cuba", Arbor, n.os 547-548, t. CXXXIX, CSIC, Madrid, 1991, págs. 39-54.

(47) Memorias de la Real Sociedad Patriótica de La Habana, Habana, 1975, pág. 19, y Miguel Ángel Puig-SAMPer Mulero, "Las primeras instituciones científicas en Cuba: el Jardín Botánico de La Habana", Consuelo NARANJO y Tomás Mallo (ed.), Cuba, la perla de las Antillas, Madrid, CSIC-Ediciones Doce Calles, 1994, págs. 19-34. 
quien favoreció los planes (48). Desde 1795 se había pensado en abrir las escuelas proyectadas como cátedras del seminario de San Carlos, dependiente del clero secular y más abierto a las reformas que la Universidad, en manos de los dominicos, y el obispo Espada lo modernizó hasta convertirlo «...durante un corto período, en uno de los primeros colegios de su clase en América» (49).

En 1807, Espada abrió en el Seminario una cátedra de matemáticas y otra de derecho. La primera estuvo desempeñada durante 35 años por Pedro de Abad y Villarreal, llegado a Cuba en 1802, inició el estudio de las ciencias naturales, especialmente de la física, con clases de hidroestática, e incluyó principios de arquitectura, pero en 1820 no se podía impartir el curso por falta de alumnos y terminó limitándolo a las matemáticas puras (50).

El esfuerzo por la difusión de las luces no se limitaba a la educación superior. En 1795 la Sociedad acordaba establecer una junta para crear unas escuelas gratuitas de primeras letras en La Habana y en pueblos rurales. En 1798 se abrió una en el pueblo de Güines, a modo de ensayo, con el fin de promover futuras escuelas en otras parroquias rurales que contribuyeran a mejorar las costumbres de la población blanca.

La reforma de las costumbres no podía dejar de contar con el teatro, la institución encargada de poner en práctica la máxima ilustrada de «instruir deleitando». Entre 1794 y 1803 la ciudad emprendió la tarea de reedificarlo, hasta dejar acabado un sólido edificio que permanecería en uso por más de tres décadas.

Dentro del campo de la higiene pública, el médico habanero Tomás Romay había planteado desde 1793 el papel que debía desempeñar la medicina en la prevención de enfermedades, pues la inmigración masiva de esclavos africanos hacia la ciudad y sus campos creaba focos peligrosos de epidemias tanto para la población urbana como para conservar la rique-

(48) Eduardo Torres Cuevas, Obispo Espada. Ilustración, Reforma y Antiesclavismo, La Habana, 1990, pág. 9.

(49) R. Simpson, [45], pág. 91.

(50) ANC, Legajo 21/1035, Instrucción Pública. 
za invertida en la mano de obra. La lucha contra las enfermedades debía seguir cauces científicos con la reforma de la enseñanza de la medicina y con la introducción de la vacuna contra la viruela. El uso de esta última fue impulsado como campaña por Romay y el obispo Espada, venciendo la ignorancia superstición popular y aprovechando el interés de la Corona por difundirla (51).

Otras obras de saneamiento urbano fueron llevadas a cabo paralelamente. La apertura de un cementerio fuera de las iglesias, medida decretada por la metrópoli desde años atrás y reactivada por real cédula de 1804, fue cumplida por Espada en 1806, en contra de las costumbres, al dejar terminado el primer cementerio extramuros, cerca de la Beneficencia y el Lazareto, a un costo de 46.000 pesos bajo la dirección del arquitecto francés Esteban Hallet (52). La separación del matadero fuera del recinto urbano para situarlo en 1797 junto a la calzada de Monte por donde penetraba el ganado, y el inicio en 1804 del empedrado general de la ciudad, contratando al francés Bailly a un costo de 152.000 pesos (53), la desecación realizada por el mismo de la ciénaga cercana a la ciudad, constituyeron pasos importantes en pos de un concepto nuevo de ciudad limpia y ordenada. El sucio aspecto del mercado al aire libre fue movido de su sitio céntrico en la Plaza Nueva durante 14 años y distribuido en varios espacios públicos, creando una organización más extendida, razonable y práctica del abastecimiento diario.

Surgía una conciencia vergonzante de la imagen urbana ante la mirada del forastero y una inclinación hacia el decoro y la dignidad local que implicaba una comparación con las ciudades más adelantadas de Europa y América. La ciudad heredada

(51) José López SÁnchez, Tomás Romay y el origen de la ciencia en Cuba, La Habana, 1964, pág. 19.

(52) El plano del cementerio fue enviado al obispo con la real cédula de 1804, de acuerdo a un esquema común para toda América Hispana. Pero según Romay «...Era éste tan conforme al que se había adoptado, que nada hubo que innovar", Tomás RomaY, Descripción del cementerio general de La Habana, La Habana, 1806.

(53) Antonio BACHILler y. Morales, Historia de las medidas adoptadas por la administración para la conservación de las calles, Habana, 1860, pág. 7. 
de la tradición se contemplaba con insatisfacción. La vida cotidiana ordenaba sus ritmos y una disciplina más rigurosa trataba de eliminar los efectos del desorden social en aras de una caracterización más limpia y racional de los espacios y de la arquitectura, cargada de un nuevo espíritu de elevación moral y rectitud.

El profesor de matemáticas del seminario confeccionaba un texto para regular los toques de campanas, horario que señalaba el acontecer diario, con tablas y reglas para regir el transcurso del día natural (54). Las ruidosas procesiones que acompañaban diariamente el Rosario, las del Corpus, las organizadas por negros y mulatos durante la Semana Santa, fueron eliminadas o reducidas para evitar escenas indecorosas como contemplar a los marinos extranjeros considerados herejes, lanzando monedas al paso de la salve para hacer bailar a negros y muchachos (55). La vida civil se trataba de regular de modo semejante mediante el dictado habitual de los bandos de gobierno que ejercieron una acción represiva contra algunas costumbres populares prohibiendo la actividad de los cabildos de los negros libres en zonas céntricas y hacer altares de santos o entierros de negros con sus bailes de nación (56).

La reforma de la división territorial de la ciudad en 1807 estaba dirigida a ejercer un control más estricto de los barrios. La ciudad intramuros pasó a tener ocho cuarteles más, con un total de 16, y los arrabales se dividieron en tres partidos, al mismo tiempo que el gobierno tomaba medidas para destruir la solidaridad de los negros y mulatos en bandos o barriadas que dividían a la ciudad con áreas de denominación tradicional como Cangrejo, Campeche, la Pluma, en torno a los templos y cofradías (57). La delimitación militar del cuerpo urbano evolucionaba hacia una nueva línea defensiva que permitiera asimilar los barrios de extramuros. En 1795 el

(54) Pedro Abad y Villarreal, Reloj Perpetuo, La Habana, 1814.

(55) "Obispo Espada. Quejas y acusaciones», Archivo González del Valle, Colección Manuscritos, Instituto de Literatura y Linguiística, La Habana.

(56) Dolores GonZÁlEZ-RIPOLL, "Voces de gobierno: los bandos del capitán general Luis de las Casas», op. cit., [46], pág. 149.

(57) Francisco CARTAS, Recopilación histórica y estadística de la jurisdicción de La Habana, Habana, 1856, pág. 30. 
proyecto de canal había despertado la idea de convertir esta línea en un foso utilizando las corrientes del mismo, lo que hacía posible vender en solares los terrenos del glacis, idea que dejaba planteada la tendencia dominante en el ordenamiento del casco urbano en el siglo siguiente (58).

\section{Neoclasicismo y BUEN GUSto}

En 1792 el presbítero Caballero había señalado los inconvenientes del quehacer constructivo tradicional y sus efectos negativos sobre la ciudad: calles convertidas en lodazales durante la lluvia, ventanas salientes que restaban claridad a los espacios públicos, fuentes sucias, paseos áridos y sin adornos, y sobre todo, edificios muy lejanos de «la idea del buen gusto y la ilustración» (59).

Los recién concluidos edificios de Gobierno de la Plaza de Armas, mayor esfuerzo desplegado en la ciudad en materia de edificios civiles, no eran más que "...montañas de piedra labrada que presentan cierta idea confusa de grandeza...» e "...hinchada ostentación exterior...». En los templos «...no se ven sino extravíos y caprichos de infelices imaginaciones desarregladas (...) altares en que no hay género de extravagancias que los artífices no ejecuten". Las viviendas por su parte no andaban mejor: "La manía de las portadas, adornos rehundidos, y resaltos de pésimo dibujo con que pretenden engalanar las más considerables, son una especie de mascarones, que hacen monstruosa la cara de un cuerpo regular. Pero lo que más desgracia son esos tremendos balcones, esos enmaderados a modo de andamios, estos edificios en el aire y como pegados a otros edificios que oscurecen y quitan la ventilación a las calles, y en fin en pocos años dan a las mejores casas un aspecto de ruinosa vejez".

Por tanto, las nuevas obras, animadas de un propósito de mejoramiento social, fueron concebidas ahora dentro de un estilo diferente a la confusa y. dinámica decoración del barro-

(58) Op. cit., [25]

(59) Op. cit., [40].

R. I., $1996, \mathrm{n} .^{\circ} 207$ 
co-tardío y la carpintería mudéjar que imperaba entonces en la ciudad, y se inclinaron a una simplicidad más racional, inspirada en la legitimidad del estilo neoclásico de acuerdo a las reglas de la ilustración académica y que funcionaba por razones de su contenido histórico como un estilo invocador de virtudes civiles. La Casa de Beneficencia, delineada por el ingeniero militar italiano Francisco Wambitelli tuvo entre sus condicionantes la de ser un edificio «alto, fuerte y de hermosa sencillez» (60). Fue esta la primera obra de estilo clásico ejecutada en la Isla, pues con anterioridad sólo había sido proyectada en formas neoclásicas la iglesia de Güines dentro del proyecto general para la villa del ingeniero Huet, nunca realizado (61).

Tanto la Beneficencia como el Cementerio de Espada, también diseñado en estilo neoclásico, fueron obras que por su naturaleza social se encontraron apartadas del cuerpo urbano y su presencia no fue tan efectiva sobre la población. La modificación del ambiente urbano y el marco de la vida diaria de acuerdo a una imagen más clara y disciplinada era un proceso lento que se contaría por décadas y que la Iglesia desempeñó un papel decisivo como catalizador de la transformación del grupo y la sensibilidad popular, y también del ritual social. La modificación de los objetivos del culto (templos, altares e imágenes) ejercía un efecto educativo directo sobre la población. En 1803 el obispo decretó la eliminación de las cruces en las calles y la sustitución de los crucifijos irregulares en las iglesias por otros mejor proporcionados. Contrató al pintor italiano José de Perovani para la decoración de la catedral y la iglesia del Espíritu Santo. La fachada de la iglesia conventual de

(60) Noticia del origen y progreso de la fundación de la Casa de Beneficencia, La Habana, s/f, Biblioteca Nacional "José Martí». El plano de la obra también se ha atribuido a Águstín Ibarra, ingeniero militar que llegó a ser director de la Sociedad Económica en 1813.

(61) «El conjunto, evidentemente -afirma María Sánchez Agustí con respecto a la Beneficencia-, se encuadra dentro de los cánones de la arquitectura neoclásica que desde hacía tiempo se venía ejecutando en España y Europa. No olvidemos que su autor se había formado bajo las órdenes de Francisco Sabatini en las obras del Palacio Real y en la ampliación del Palacio de Aranjuez», Edificios públicos de La Habana en el siglo XVIII, Valladolid, 1984, pág. 76. 
Santa Clara fue transformada en orden dórico, y, en la segunda década del siglo xix, Pedro Abad y Villareal emprendía dos obras neoclásicas de trascendencia: los nuevos altares de la Catedral y la fachada del templo de Nuestra Señora de Regla, la Virgen negra patrona de la bahía, puntos focales de la devoción habanera. Esta última obra serviría de modelo a otras iglesias similares levantadas o modificadas en las poblaciones cubanas en lo adelante al combinar la fachada clásica con un interior de armaduras de madera al uso tradicional. La portada del templo, al igual que las de la Beneficencia y del Cementerio, seguía las líneas del arco del triunfo romano, esquema común desde tiempos de Alberti.

La obra de los ingenieros militares, en su mayoría egresados de la Academia de Barcelona, de los franceses emigrados, y de los hacendados y comerciantes más cultos e inmersos en el espíritu de la Ilustración, abrió el paso al germen de un nuevo estilo, universal y de formas clásicas, encaminado a la renovación y actualización de la capital y que a partir de entonces comenzaría lentamente a caracterizar su ambiente y el de otras ciudades de su región.

\section{A MODO DE CONCLUSIÓN}

El esfuerzo de los hacendados habaneros por organizar su región de acuerdo a las necesidades de la plantación esclavista no tuvo un respaldo financiero por parte de la Corona española. Las iniciativas de los hacendados más despiertos se canalizaron a través de las instituciones ilustradas al uso, pero sin recursos para enfrentar planes tan ambiciosos. En este sentido el primer impulso reformista estuvo muy comprometido con el ambiente ilustrado de la metrópoli y se encaminó hacia el aprovechamiento de sus recursos intelectuales, pero encontró poco ánimo para secundar las amplias miras de los criollos. La oposición entre hacendados y comerciantes no siempre puede traducirse como oposición entre reformistas y conservadores. Un sector del comercio tuvo intereses como productores y actuó también como propulsor de las reformas en la isla, sobre todo, un grupo de comerciantes y funcionarios de origen vasco.

R. I., 1996, n. 207 
La esclavitud por su parte hizo pagar su precio a la anhelada independencia económica del reformismo habanero. Ningún proyecto tomaba en cuenta los efectos a largo plazo de la introducción masiva de esclavos africanos como elementos integrantes de la sociedad. Era un mal necesario donde la racionalidad ilustrada no hallaba eco, asumido con plena conciencia de sus limitaciones para el ascenso de una clase social que daba inicio a su trayectoria. Sobre esa zona de silencio que constituía la esclavitud sólo se proyectaban medidas represivas para conjurar el temor al ejemplo haitiano por medio del poblamiento y la seguridad de los campos, la exclusión de negros y mulatos de los planes educativos o de los cuerpos de milicias.

Los proyectos de los hacendados habaneros estaban escindidos entre la especulación ideal de un deber ser, un modelo racional autosuficiente, y una acción más real y práctica que se va imponiendo con resultados de menor alcance, limitados, con un saldo de frustración o de experiencia inacabada o pospuesta.

El uso de los recursos hidráulicos fue la primera de estas soluciones ideales, promesa que resolvía los problemas del transporte, fertilidad de los campos, energía, haciendo del ingenio un establecimiento perdurable y aumentando producción y rendimiento. Pero la imposibilidad de aplicarlos en gran escala dejó en suspenso estos anhelos y los pospuso hasta la introducción de los resultados de las tecnologías basadas en el uso del vapor que terminaron por dominar el universo industrial del ingenio: molinos, sistemas de evaporación y extracción del azúcar, ferrocarriles, navegación de cabotaje a vapor.

La expansión territorial autoimpulsada por la plantación y su cultivo extensivo siguió su curso al este de la Isla y extendió sus fronteras. Las tierras abandonadas por el cultivo de la caña se transformaban en zonas de abastecimientos agrícolas para el consumo de la capital y las ciudades mayores, entre ellas las del fértil valle de Güines (62), quedando en manos de un campesinado libre. Las poblaciones que el crecimiento azucarero diseminó por la región se convirtieron en centros de formas de

(62) Julio Le Riverend, La Habana. Biografía de una Provincia, La Habana, 1960 , págs. $240-241$. 
vida urbana libre, y fueron estableciendo un programa urbano de menor escala con sus iglesias de una sola nave, cementerios, escuelas, y una estructura de servicios basadas en almacenes, tiendas mixtas, fondas-posadas, billares, vallas de gallos, que dominaba la vida de un caserío a veces escaso y satisfacía las necesidades de una población rural dispersa. En ellas se hicieron más cercanas las relaciones entre los distintos grupos étnicos y su importancia residual se acrecentaba en la medida que el ingenio se alejaba o desaparecía dejando paso a otras formas de vinculación con la tierra. La existencia de estos poblados interiores se transformó en algo muy diferente de las antiguas villas y ciudades con sus cabildos y extensas jurisdicciones desoladas repartidas en hatos y corrales. Sobre ellos se sostuvieron sentimientos $\mathrm{y}$ actitudes señoriales $\mathrm{y}$ paternalistas $\mathrm{y}$ otras más humildes y fraternas propias de pequeños campesinos agrupados en comunidades y caseríos menores (63).

La fundación de nuevas poblaciones y el poblamiento interior hizo más corta la distancia demográfica entre la capital y el resto del país que en períodos anteriores y desplazó el interés de la urbanización fuera de sus límites. La ciudad creció a un ritmo más lento que su región. En $1778 \mathrm{La}$ Habana tenía el $23 \%$ de la población de Cuba y en 1792 sólo el $16 \%$. El crecimiento relativo de la ciudad y sus arrabales con respecto a la jurisdicción también disminuyó (64):

\begin{tabular}{lrr}
\hline & Ciudad & \multicolumn{1}{c}{ Región } \\
\cline { 2 - 3 } 1774 & 45.071 & 61.372 \\
1792 & 51.307 & 151.130 \\
1817 & 84.075 & 296.147 \\
\hline
\end{tabular}

(63) Se ha querido ver en el plan de fundación de estas poblaciones una intención de los hacendados reformistas por establecer futuros centros de población campesina que sustituyeran la esclavitud. Eduardo ToRres-CuEvas, "Los reformismos cubanos: de Arango y Parreño a Pozos Dulces", Ramón de la Sagra y Cuba. Actas del Congreso celebrado en París, Enero 1992, vol. 1, La Coruña, 1942, pág. 47.

(64) Juan PÉREZ DE LA RIVA, "Desarrollo de la población habanera», Bohemia, n. 46, La Habana, 1965, pág. 100.

R. I., 1996, n. ${ }^{\circ} 207$ 
La necesidad de contar con información estadística y conocimientos objetivos sobre los efectos de la emigración africana, el desarrollo de las nuevas poblaciones y sus partidos, dio lugar a la aparición de los primeros análisis demográficos como la "Nota sobre la población de la Isla de Cuba» de Antonio del Valle Hernández, secretario de la Sociedad Económica, escrita hacia 1810, y a una serie de memorias sobre las localidades que culminaban en 1813 con un cuestionario cursado a todas las localidades del país con el fin de redactar un diccionario geográfico e histórico del mismo (65). Una nueva conciencia urbana comenzaba a despertar y a fomentar el aprecio por los recursos naturales, el paisaje y la historia de las localidades de la Isla. Desde las instituciones de su capital emanaba un concepto del país unitario en función de los intereses de su élite urbana de comerciantes y hacendados.

El propósito de lograr un desarrollo regional equilibrado con nuevos puertos abiertos al crecimiento azucarero y La Habana como centro receptor, se convirtió en una realidad contradictoria; las antiguas jurisdicciones del oriente y centro de la isla, se encontraron marginadas de la riqueza azucarera, supeditadas a los intereses de la región habanera, acrecentándose el desequilibrio entre una y otra parte de la Isla. La capitalidad de La Habana identificó los intereses y aspiraciones de un sector privilegiado con los destinos del país.

Between 1790 and 1810, Havanna and its surrounding area witnessed a fast growth of sugar production based on slave-holding plantations. This promoted the idea of planning the system's expansion over a wider area in different dimensions, such as settlement distribution, workforce and energy sources needed, communications and transportation required, the concomitant urban planning, etc., all of which were seen for the first time as parts of a single program, thought out under

(65) «Descripción de los pueblos de la Isla de Cuba», Colección de Manuscritos, Morales, tomo 13, n.o 5, Biblioteca Nacional "José Martí». Aunque el diccionario no llegó a publicarse una obra similar fue realizada por Jacobo de la Pezuela y editada en Madrid en 1861 en cuatro tomos, tal vez el autor asimiló en ella la información recogida desde entonces. 
the reformist spirit of the Enlightenment. The author discusses the initiatives taken, the people involved, and the contributions put into effect. He intends to assess the significance of this moment of intellectual takeoff concerning the urban organization of Havanna and its region.

R. I., 1996, n.o 207 